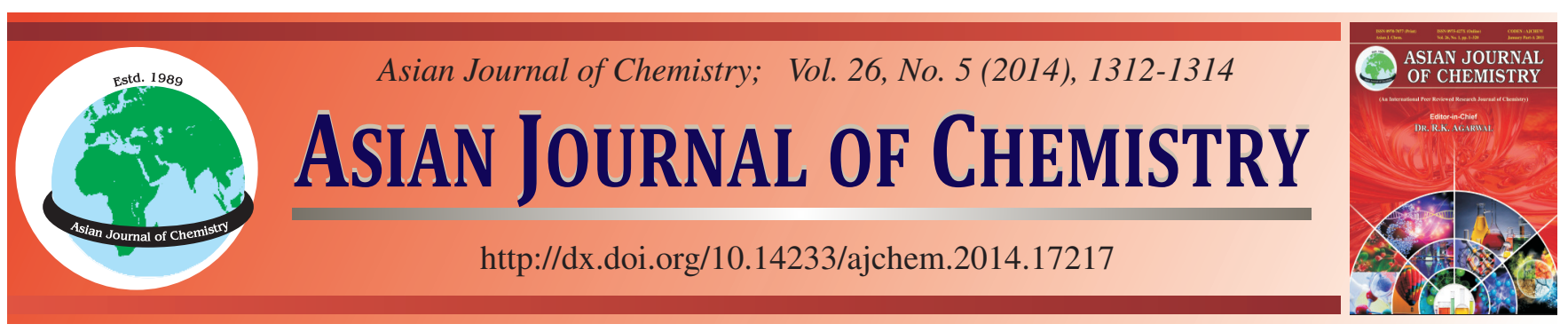

\title{
Thermal Properties of Normal and Light-Weight Aggregate Concrete with Elevated Temperature and Loading $\dagger$
}

\author{
Gyu Yong KIM ${ }^{1}$, TAe Gyu LeE ${ }^{1, *}$, YeOnwoo KAnG ${ }^{2}$ and SAngsoo LeE ${ }^{3}$
}

${ }^{1}$ Department of Architectural Engineering, Chungnam National University, Daejeon, Republic of Korea

${ }^{2}$ Architecture Technical Team, DSME Construction Co., Ltd., Seoul, Republic of Korea

${ }^{3}$ Department of Architectural Engineering, Hanbat National University, Daejeon, Republic of Korea

*Corresponding author: Fax: +82 42 8239467; E-mail: ninga777@naver.com

Published online: 1 March 2014;

AJC-14758

This study was conducted for $\emptyset 100 \times 200 \mathrm{~mm}$ specimens. The experiment was conducted at $20-700{ }^{\circ} \mathrm{C}$ in the state that the loads of 0,20 and $40 \%$ of compressive strength at room temperature were applied. The evaluation items included thermal strain, total strain and transient creep subjected to high temperature. The results of experiments showed that it was found that the transient creep by loading is constant regardless of the type of aggregate below $500{ }^{\circ} \mathrm{C}$. However over $500{ }^{\circ} \mathrm{C}$, the higher the thermal expansion coefficient of aggregate is, the transient creep by loading increases rapidly.

Keywords: Thermal strain, Crack, High temperature, Restraint force, Shrinkage strain.

\section{INTRODUCTION}

In order to estimate the behaviour of concrete structures under high temperature, thermal properties of various materials such as aggregate, cement paste and admixture should be sufficiently reflected. Generally, the mechanical behaviours of concrete are described by theory of elasticity.

The concrete subjected to high temperature expands or contracts according to thermal properties of the components. In case of concrete when it is subjected to high temperature, it shows nonlinear behaviour by effects of spalling, reduction of compressive strength and elastic modulus and transient creep $^{1-3}$. Effect of thermal properties of aggregate on concrete is very high. Therefore, CEN and CEB Codes suggest the models for performance-based fire safety design for normal weight aggregate concrete and light-weight aggregate concrete, considering thermal properties of aggregate ${ }^{4}$.
The aim of this study is to investigate the effect of high temperature and loading on thermal properties such as stressstrain curve, strain at peak stress and thermal strain. In addition, it aims to provide the actual data for performance-based fire safety design by analyzing the effect of thermal strain of aggregate and shrinkage strain by loading on mechanical properties of concrete.

\section{EXPERIMENTAL}

The physical properties of materials used in this study are given in Table-1. The types of coarse aggregate included granite, ash-clay and clay aggregates.

The thermal expansion coefficients of coarse aggregate according to temperature are shown in Table-2.

Concrete: In this study, concretes are made by using granite, ash-clay and clay aggregate, respectively, which are

\begin{tabular}{lccccc}
\multicolumn{7}{c}{ TABLE-1 } \\
\cline { 4 - 6 } \multicolumn{1}{c}{ PHYSICAL PROPERTIES OF MATERIAL } \\
\cline { 3 - 7 } Physical properties & PC & SF & Granite & Coarse aggregate \\
\hline Specific surface $\left(\mathrm{cm}^{2} / \mathrm{g}\right)$ & 3,160 & 200,000 & - & - & - \\
Specific gravity & 3.1 & 2.2 & 2.67 & 1.68 & 1.79 \\
Size $(\mathrm{mm})$ & - & - & 20.00 & 13.00 & 13.00 \\
Absorption $(\%)$ & - & - & 1.00 & 15.20 & 17.40 \\
\hline
\end{tabular}

†Presented at The 7th International Conference on Multi-functional Materials and Applications, held on 22-24 November 2013, Anhui University of Science \& Technology, Huainan, Anhui Province, P.R. China 
TABLE-2

COEFFICIENT OF THERMAL EXPANSION $\left(\times 10^{-6} /{ }^{\circ} \mathrm{C}\right)$

\begin{tabular}{cccccccccc}
\hline Aggregate & \multicolumn{10}{c}{ Heating temperature $\left({ }^{\circ} \mathrm{C}\right)$} \\
\cline { 2 - 9 } type & 20 & 100 & 200 & 300 & 400 & 500 & 600 & 700 \\
\hline Granite & 6.1 & 4.8 & 7.4 & 9.8 & 12.2 & 14.5 & 21.1 & 21.2 \\
Ash-clay & 4.3 & 3.5 & 3.2 & 3.6 & 4.0 & 4.4 & 5.2 & 4.7 \\
Clay & 5.7 & 5.2 & 5.8 & 6.2 & 6.5 & 6.8 & 8.1 & 7.5 \\
\hline
\end{tabular}

designated as GC, AC and CC, respectively. The mixing and fresh state of concrete are showed in Table-3. The concrete mixing was set to keep coarse aggregate at a constant volume. As for water to binder, it was set as 0.35 for GC and 0.33 for $\mathrm{AC}$ and $\mathrm{CC}$, respectively. The light-weight concrete has low strength development compared to normal weight aggregate concrete.

\begin{tabular}{lccc}
\multicolumn{4}{c}{ TABLE-3 } \\
PROPORTION OF THE CONCRETE MIXTURES \\
\multicolumn{2}{c}{ AND PROPERTIES OF THE FRESH CONCRETE } \\
\hline \multicolumn{1}{c}{ Concrete type } & GC & AC & CC \\
\hline Water $/$ cement & 0.35 & 0.33 & 0.33 \\
Water $\left(\mathrm{kg} / \mathrm{m}^{3}\right)$ & 165 & 155 & 155 \\
Cement $\left(\mathrm{kg} / \mathrm{m}^{3}\right)$ & 470 & 432 & 432 \\
Silica fume $\left(\mathrm{kg} / \mathrm{m}^{3}\right)$ & - & 38 & 38 \\
Fine aggregate $\left(\mathrm{kg} / \mathrm{m}^{3}\right)$ & 692 & 687 & 687 \\
Granite $\left(\mathrm{kg} / \mathrm{m}^{3}\right)$ & 1,075 & - & - \\
Ash-clay $\left(\mathrm{kg} / \mathrm{m}^{3}\right)$ & - & 676 & - \\
Clay $\left(\mathrm{kg} / \mathrm{m}^{3}\right)$ & - & - & 720 \\
Unit weight $\left(\mathrm{kg} / \mathrm{m}^{3}\right)$ & 2,410 & 1,958 & 2,031 \\
Slump $(\mathrm{mm})$ & 190 & 180 & 175 \\
Air content $(\%)$ & 3.3 & 3.5 & 3.6 \\
\hline
\end{tabular}

Preparation of specimen: For evaluating mechanical properties at a high temperature, we manufactured $\varnothing 100 \times$ $200 \mathrm{~mm}$ specimens. The specimens were cured under water for 7 days, then air dry curing was conducted up to 180 days at a steady temperature and humidity chamber set as $20 \pm$ $2{ }^{\circ} \mathrm{C}$, R.H. $50 \pm 5 \%{ }^{5}$.

Test methods: An electric heating furnace was installed in the $2,000 \mathrm{kN}$ capacity UTM loading machine so that loading and heating may be carried out simultaneously.

Fig. 1 shows heating curve of this study. The heating velocity was conducted at the temperature below $1{ }^{\circ} \mathrm{C}$, referring to previous studies and RILEM Code ${ }^{6,7}$. In order to heat concrete specimens at uniform temperature, the range from room temperature $\left(20^{\circ} \mathrm{C}\right.$ ) to $50^{\circ} \mathrm{C}$ and the range from $50{ }^{\circ} \mathrm{C}$ before reaching the target temperature were heated at $0.77^{\circ} \mathrm{C} /$ $\mathrm{min}$ and the other ranges were heated at the heating velocity of $1{ }^{\circ} \mathrm{C} / \mathrm{min}$. In addition, it was set for the temperature difference between the inside and the outside to be within $5^{\circ} \mathrm{C}$ by keeping it at target temperature for $1 \mathrm{~h}$.

In accordance with (Part 6-Thermal Strain) of RILEM TC 129-MHT, strain properties were measured and thermal behaviours of concrete at fire were analyzed ${ }^{6}$. The transient creep was calculated in accordance with (Part 7-Transient Creep) of RILEM TC 129-MHT ${ }^{7}$. The strain at peak stress was evaluated by the method presented in EN 1992-1-2:2004(E).

\section{RESULTS AND DISCUSSION}

Strain of concrete: Fig. 2 shows the thermal strain and total strain of concrete. Unstressed condition, for GC, the

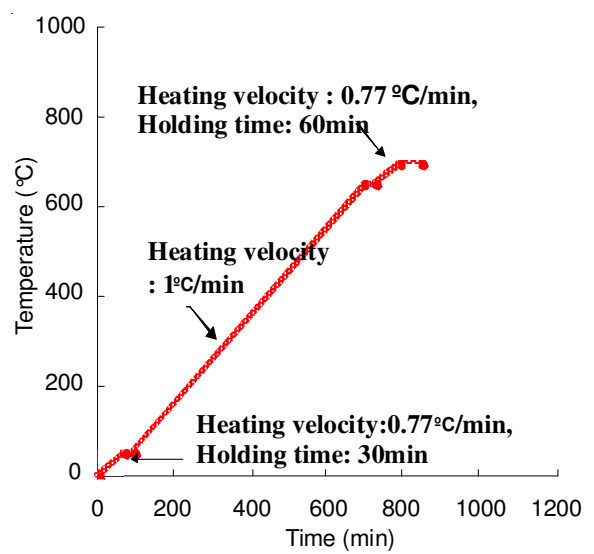

Fig. 1. Heating method

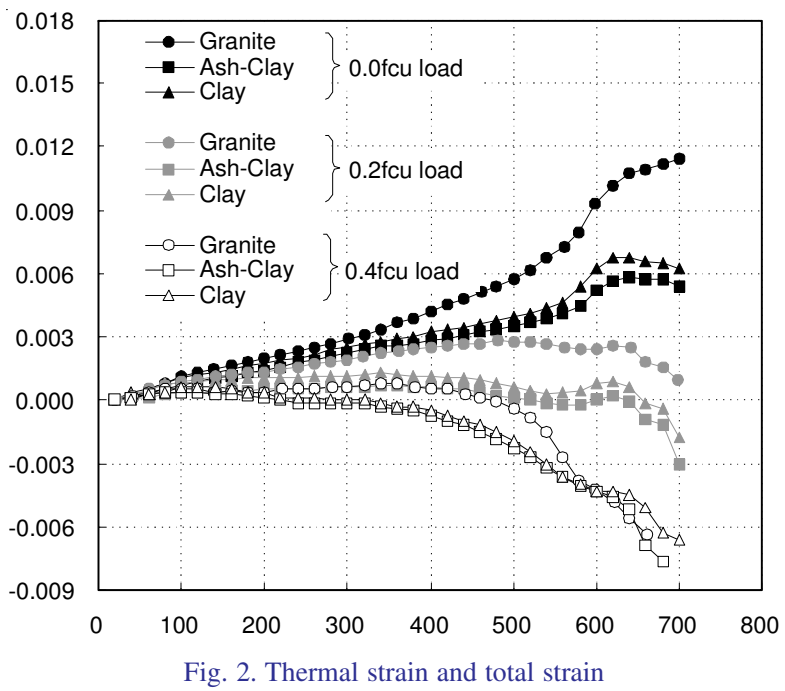

thermal expansion coefficient increased with elevated temperature. Ultimately, it showed the thermal expansion coefficient of 0.0012 at $700{ }^{\circ} \mathrm{C}$. GC shows the value between siliceous and calcareous aggregates.

As the thermal expansion coefficient is about a quarter compared to granite aggregate, in case light-weight aggregate is used to make concrete, it has smaller thermal strain than GC.

While, the thermal strain of $\mathrm{AC}$ at $700^{\circ} \mathrm{C}$ is 0.006 , which is $50 \%$ compared to GC and twice higher than 0.003 , the thermal strain of aggregate. It is estimated as a phenomenon which occurs by increase of thermal stress due to formation of micro-structures as silica fume replaces $8 \%$ of the cement weight in order to develop the prescribed strength.

Stressed condition, in case concrete is subjected to the loads of 0.2 and $0.4 \mathrm{fcu}$, the thermal strain of concrete is significantly controlled in general. GC was subjected to the load of $0.2 \mathrm{fcu}$, the strain continued to increase by $300^{\circ} \mathrm{C}$ and the strain convergence at 0.003 above $300{ }^{\circ} \mathrm{C}$. Under the load 
condition of $0.4 \mathrm{fcu}$, a little increase of the strain or was kept by $400{ }^{\circ} \mathrm{C}$, then it was rapidly shrunk above $500{ }^{\circ} \mathrm{C}$ and failed at $700{ }^{\circ} \mathrm{C}$. In case of $\mathrm{AC}$ and $\mathrm{CC}$, unlike $\mathrm{GC}$, they kept the shapes of specimens before heating without thermal strain under the load condition of $0.2 \mathrm{fcu}$, whereas in case of being subjected to the load of $0.4 \mathrm{fcu}$, it was rapidly shrunk above $300{ }^{\circ} \mathrm{C}$ and the strain increased.

Fig. 3 shows the transient creep of concrete specimens to which loads and heat are applied. The transient creep constantly increased with temperature and it showed rapid shrinkage over $500{ }^{\circ} \mathrm{C}$. Thus, it is analyzed that as for the transient creep, the effect of load is big below $500{ }^{\circ} \mathrm{C}$, while the effect of temperature is dominating over $500{ }^{\circ} \mathrm{C}$.

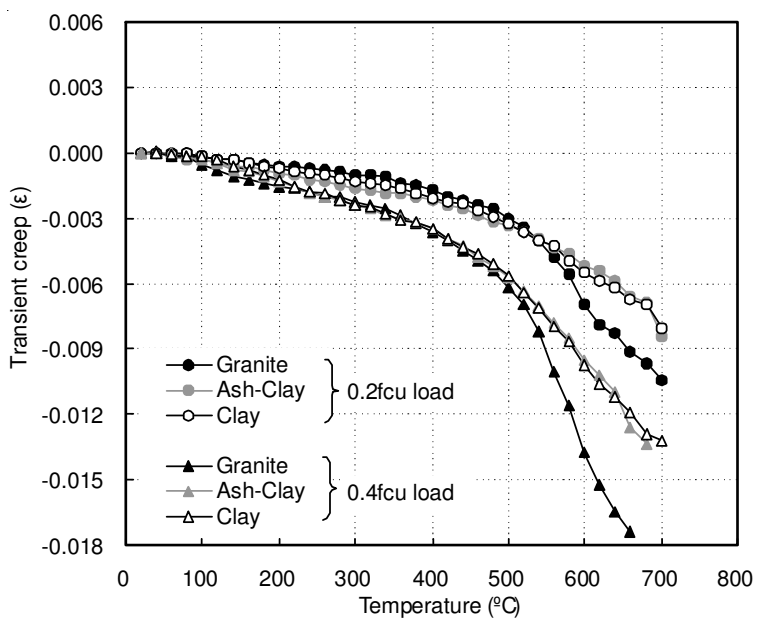

Fig. 3. Transient creep strain

For analyzing this, the thermal strain of concrete and the strain at maximum stress were compared and the results are shown in Figs. 4-6. As a result, it has been confirmed that the larger the residual strain of concrete is, the lower the residual ratio of strength is and the larger the thermal strain of aggregate is, the greater the effect is.

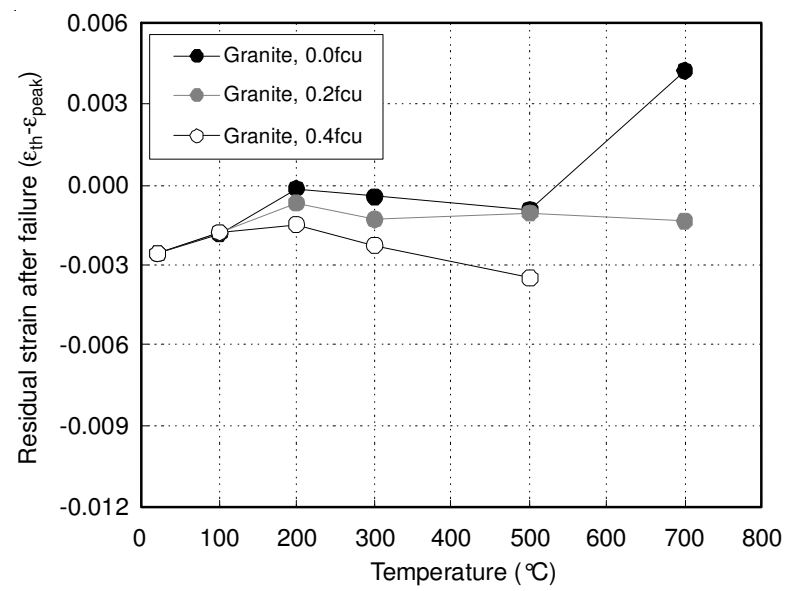

Fig. 4. Status of concrete after failure GC

\section{Conclusion}

With the increase in load, the concrete changes to shrinkage. The transient creep is small in case shrinkage strain by load is more influential than thermal expansion strain of aggregate. The transient creep is similar, regardless of the type

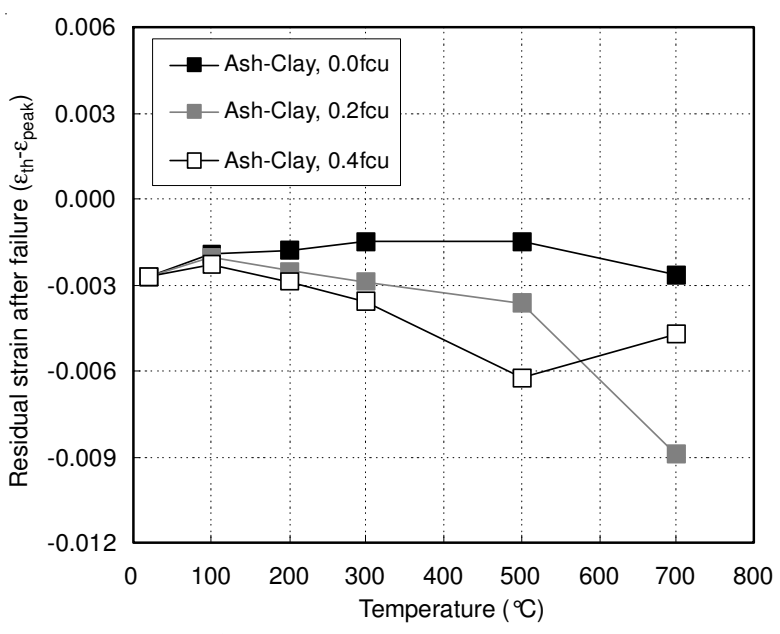

Fig. 5. Status of concrete after failure AC

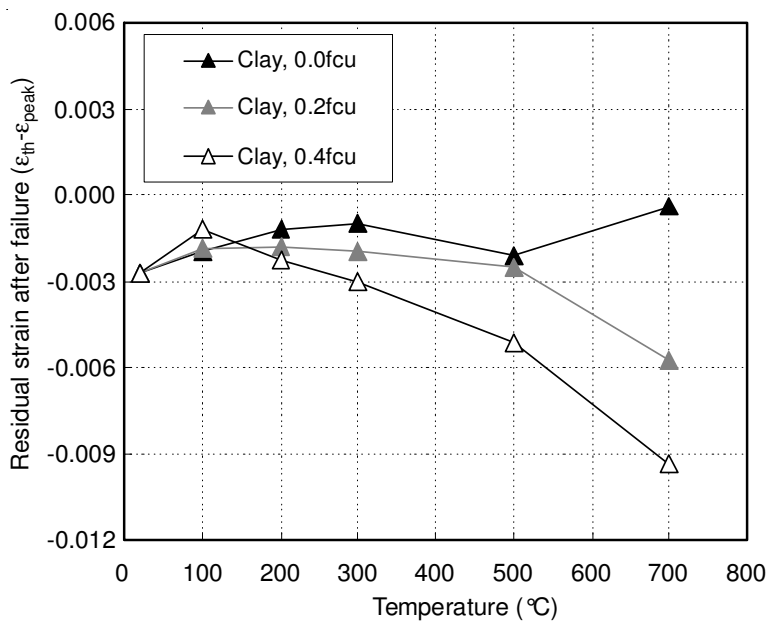

Fig. 6. Status of concrete after failure CC

of aggregate at the temperature below $500{ }^{\circ} \mathrm{C}$. Over $500{ }^{\circ} \mathrm{C}$, the concrete having high thermal strain of aggregate has rapid increase of transient creep along with the increase of load. If thermal strain of concrete is small and the load of 20-40\% is applied to it, the elastic deformation of concrete is kept, by which the transient creep is declined.

\section{ACKNOWLEDGEMENTS}

This work was supported by the National Research Foundation of Korea(NRF- 2010-0014723) grant funded and Brain Korea 2th (BK21) by the Korea government (MEST).

\section{REFERENCES}

1. G. Kim, Y. Kim and T. Lee, J. Asian Archit. Building Eng., 9, 431 (2010).

2. G.-Y. Kim, Y.-S. Kim, T.-G. Lee and M.-K. Yoon, J. Korea Concrete Instit., 20, 583 (2008).

3. V.K.R. Kodur and M.A. Sultan, J. Mater. Civil Engin. ASCE, 15, 101 (2003).

4. Committee European de Normalisation (CEN), prENV 1992-1-2: Eurocode 2: Design of concrete structures. Part 1-2: Structural Fire Design, CEN/TC 250/SC 2 (1993).

5. RILEM Technical Committee, Compressive strength for service and accident conditions, Mater. Struct., 28, 410 (1995).

6. RILEM Technical Committee recommendation, Part 6 Thermal strain, Mater. Struct., 30S, 17 (1997).

7. RILEM Technical Committee recommendation, Part 7 Transient Creep for service and accident conditions, Mater. Struct., 31, 290 (1998). 